\title{
A METISERGIDE NO TRATAMENTO DA EPILEPSIA TEMPORAL
}

\author{
Jorge ARMBrust-Figueiredo *
}

Ao estudarem a ação da metisergide sôbre as cefaléias vasculares, Hale e Reed ${ }^{5}$, em 1962, verificaram que alguns pacientes que apresentavam alteraçōes eletrencefalográficas compativeis com enxaqueca, tinham seus traçados normalizados após tratamento com essa droga. Sugeriram, então, possível eficácia dêsse agente no contrôle de distúrbios convulsivos.

Em 1965, Armbrust-Figueiredo e col. ${ }^{2}$ observaram efeito semelhante, ao empregarem a metisergide em um grupo de 48 pacientes com enxaqueca. As alteraçōes do EEG, presentes em 24 casos antes do inicio do tratamento, desapareceram ao fim de um mês, em elevada percentagem dos casos.

Tais achados, confirmando as suspeitas de Hale e Reed, levaram-nos a experimentar a droga em pacientes com crises epilépticas.

\section{MATERIAL E METODO}

Estudamos 78 pacientes com crises psicomotoras e cujos EEG mostravam atividade focal anormal (ondas "sharp") de projeção em um dos lobos temporais. Dêstes, 30 já haviam sido tratados prèviamente em nosso Serviço com drogas anticonvulsivantes, mas continuavam apresentando crises e os seus EEG persistiam com alterações focais. Os outros 48 não se haviam submetido a tratamento específico de modo regular, antes de procurarem nosso Serviço pela primeira vez.

Todos os pacientes apresentavam crises psicomotoras, simples ou complexas, e na história pregressa de cada um dêles havia referência a parto traumático.

Dos 78 pacientes, 42 eram do sexo feminino; suas idades variavam entre 16 e 36 anos, e o tempo de duração das crises, de 6 a 18 anos.

Os exames neurológicos dos pacientes foram normais, exceto em 32 nos quais foi constatada hemi-hipotrofia corporal, atribuida ao traumatismo de parto.

Os EEG foram realizados em aparelho Grass ou Kaiser, de 8 canais, colocando-se os eletrodos conforme a técnica usual internacional, com derivaçōes mono e bipolares. Os exames foram sempre realizados antes do inicio do tratamento e repetidos ao fim de $1,3,6$ e 12 meses.

A metisergide* (butanolamida do ácido 1-metil-lisérgico) foi empregada em doses que variaram de 2 a $6 \mathrm{mg}$ diários, de acôrdo com as necessidades de cada paciente e foi sempre associada a um barbitúrico (fenobarbital), administrado em uma única dose de $0,1 \mathrm{~g}$ à noite.

Departamento de Neurologia da Faculdacie de Medicina de Ribeirão Prêto da Universidade de São Paulo: * Professor Catedrático.

* Deserila, fornecida por Sandoz Brasil S.A. 
A avaliação dos resultados cínicos foi feita através de entrevistas com os pacientes e seus familiares, durante as quais obtivemos informaçōes sôbre o número e intensidade das crises, sôbre a freqüência das diferentes manifestaçōes que ocorriam durante as crises e sôbre os distúrbios de tipo psíquico.

O tempo de observacão dos pacientes foi de 12 meses.

\section{RESULTADOS}

Nossos resultados foram considerados sob dois aspectos: o efeito da droga sôbre as manifestações clínicas e sua ação sôbre o EEG.

Manifestaçoes clínicas - Dos 78 pacientes, 59 (76\%) responderam de modo favorável ao tratamento, sendo que $47(61 \%)$ nāo mais apresentaram crises e 12 (15\%) mostraram sensivel melhora, com diminuição acentuada da freqüência e da intensidade das crises. Os restantes 19 pacientes apresentaram pouca ou nenhuma influência à terapêutica.

A comparacão dos resultaclos obtidos nos dois grupos de pacientes, representados na tabela 1 , mostra que o grupo tratado pela primeira vez apresentou resultados mais satisfatórios quc o grupo submetido a tratamento especifico anterior.

\begin{tabular}{|c|c|c|c|c|c|c|}
\hline & & & \multicolumn{4}{|c|}{$R e s u l t a d o s$} \\
\hline & & & Sem & crises & Melhorados & Inalterados \\
\hline Grupo & A $\quad \mathbf{3 0}$ & pacientes) & & 16 & 5 & 9 \\
\hline Grupo & B 148 & pacientes) & & 31 & 7 & 10 \\
\hline & & Total & & 47 & 12 & 19 \\
\hline
\end{tabular}

Tabela 1 - Resultados obtidos com o emprêgo de metisergide em r8 pacientes. Grupo A: pacientes que haviam sido tratados anteriormente com anticonvulsivantes. Grupo B: pacientes que nũo haviam sido tratados de maneira regular com medicacão especifica.

O efeito benéfico da droga sôbre os 78 pacientes foi observado em diferentes épocas (tabela 2). Verificamos que já no terceiro mês, 11 pacientes não apresentavam crises há, pelo menos, 45 dias e que 24 apresentavam melhora nitida em suas manifestações críticas. No $99^{\circ}$ mês de evolução constatamos que 21 pacientes não haviam sido influenciados de maneira satisfatória pela droga, o que nos levou a incluir outros medicamentos no esquema de tratamento, excluindo-os do presente trabalho.

Ao analisarmos a freqüência de distúrbios de tipo psíquico nos 78 pacientes, antes do início do tratamento, verificamos que êles ocorriam em 62 (79\%) dos doentes. Nestes, observamos distúrbios do humor em 49, distúrbios do comportamento em 38 e crises de tipo confusional em 16. Com o tratamento, a incidência das manifestaçoes reduziu-se; 19 pacientes apresentaram melhora acentuada, sendo que $\mathrm{em} 12$ os periodos confusionais foram completamente abolidos; 22 pacientes passaram a referir episódios psíquicos menos freqüentes e os outros 21 nāo foram influenciados. Contudo, nenhum paciente apresentou agravação do quadro psíquico. 
Alteraçōes eletrencefalográficas — A avaliação do efeito da metisergide sôbre o EEG mostrou que em $29(37 \%)$ pacientes, os traçados se normalizaram, em 21 (27\%) haviam melhorado nitidamente e em 28 (36\%) permaneciam as alterações. Devemos salientar que nestes últimos 28 pacientes estão incluídos os 19 que foram excluidos do trabalho, considerando-se as condições do EEG no $9^{\circ}$ mês de tratamento.

A época de avaliação dos traçados aparece na tabela 3 .

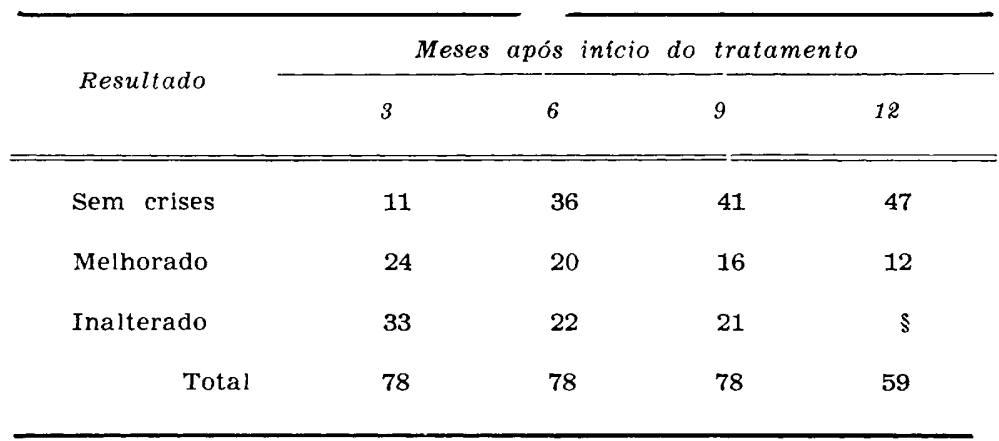

Tabela 2 - Resultados -observados durante a evolução do tratamento. $\S=19$ pacientes foram exclufdos da investigação por estarem recebendo outras drogas.

\begin{tabular}{|c|c|c|c|c|c|}
\hline & & após & início do & tratamento & \\
\hline & 1 & 3 & 6 & 9 & 12 \\
\hline Normal & & 4 & 16 & 22 & 29 \\
\hline Melhorado & 10 & 22 & 28 & 28 & 21 \\
\hline Inalterado & 68 & 52 & 34 & 28 & 28 \\
\hline
\end{tabular}

Tabela 3 - Resultados dos EEG durante a evolução do tratamento.

\section{COMENTARIOS}

Hale e Reed ${ }^{5}$ e Armbrust-Figueiredo e col. ${ }^{2}$ ao estudarem os efeitos da metisergide sôbre a enxaqueca, observaram que as alterações eletrencefalográficas presentes em alguns pacientes desapareciam ou melhoravam nìtidamente com o tratamento, sugerindo que a droga deveria ser experimentada como anticonvulsivante. Por outro lado, sabe-se de há muito, que anticonvulsivantes têm certa atividade no combate às crises de enxaqueca. Friedman e Merritt ${ }^{3}$, em 1959, chamavam a atenção para o fato de que a metilfeniletilidantoína e a difenilidantoina eram capazes de agir profilàtica- 
mente nas enxaquecas, melhorando as alteraçōes eletrencefalográficas simultânẹamente. É reconhecido, também, que alguns anticonvulsivantes, como a difenilidantoína e certos derivados da dibenzo-azepina, têm indiscutível valor terapêutico na neuralgia do trigêmeo; de modo semelhante, a metisergide atua eficazmente nessa doença ${ }^{1}$.

A semelhança de certos aspectos do comportamento terapêutico da metisergide com o dessas drogas nos levaram a experimentá-la no tratamento da epilepsia temporal.

Para o estudo selecionamos uma série homogênea de pacientes; todos eram portadores de epilepsia psicomotora com alterações focais no EEG que se projetavam em um dos lobos temporais. Para melhor avaliação comparativa, reunimos (1) pacientes que já haviam sido submetidos a prévios tratamentos sob nossa orientação, mas que não tinham obtido resultados satisfatórios com os esquemas terapêuticos propostos, e (2) pacientes que nunca haviam recebido, de maneira regular e conveniente, tratamento com drogas anticonvulsivantes.

Todos os pacientes receberam a metisergide associada ao fenobarbital, obedecendo à orientação que vimos adotando há anos e pela qual um barbitúrico deve ser obrigatỏriamente incluído em qualquer esquema terapêutico que se escolha para os diferentes tipos de epilepsia.

Os resultados que obtivemos demonstram que a metisergide age satisfatòriamente na epilepsia psicomotora devida a foco de projeção temporal. Dos 78 pacientes estudados, $47(61 \%)$ tiveram suas crises abolidas e 12 $(15 \%)$ apresentaram melhora evidente quanto à freqüência e intensidade das crises. Os 19 pacientes restantes não foram influenciados de modo satisfatório pela droga, sendo excluidos da pesquisa ao fim de 9 meses de observação.

É freqüente o fato de pacientes com epilepsia temporal apresentarem piora do quadro psíquico quando submetidos a tratamento com alguns anticonvulsivantes, particularmente a primidona. As crises de tipo motor são bem controladas, mas as manifestações de ordem psíquica são exacerbadas. obrigando, muitas vêzes, a associação de drogas psicotrópicas. Por essa razão, analisamos cuidadosamente tais sintomas, verificando que a metisergide atua de maneira eficaz, reduzindo sensivelmente os distúrbios do humor e do comportamento e as crises de tipo confusional. Por outro lado, não observamos qualquer piora dessas manifestações no grupo estudado. Efeito semelhante ao que observamos nesta investigação só foi constatado por nós com o uso do carbamil-dibenzo-azepina e da metsuximida.

A influência da droga sôbre o EEG ficou bem demonstrada. Considerando-se o número total de pacientes, inclusive aquêles que foram excluídos do trabalho ao fim de 9 meses de seguimento, verificamos que $50 \quad(64 \%)$ dos pacientes tiveram seus traçados normalizados $(37 \%)$ ou bastante melhorados $(27 \%)$.

A comparação entre os resultados clínicos e a melhora do EEG mostra que $76 \%$ dos pacientes foram influenciados clìnicamente pelo tratamento, 
ao passo que sòmente $64 \%$ mostraram regressão parcial ou total das alterações eletrencefalográficas.

A possível interferência do barbitúrico sôbre os nossos resultados não pode ser afastada. O mesmo ocorreria com a avaliação clínica dos efeitos de outras drogas na terapêutica antiepiléptica, pois não acreditamos que qualquer esquema medicamentoso possa ser suficientemente seguro se o barbitúrico não fôr nêle incluído.

As doses utilizadas foram pequenas. Empregamos doses diárias de $2 \mathrm{mg}$ inicialmente em todos os pacientes, sendo que em 14 a dosagem teve de ser elevada para $4 \mathrm{mg}$ e em 22 para $6 \mathrm{mg}$. Dêstes 22 pacientes, 19 foram excluídos do trabalho, conforme foi dito acima.

A tolerância ao medicamento foi muito boa, pois 18 pacientes apenas queixaram-se de "tontura" e mal-estar geral nos primeiros dias de tratamento e 3 referiram insônia ocasional, enquanto recebiam $2 \mathrm{mg}$ diários. Dos 36 doentes que usaram 4 ou $6 \mathrm{mg}$ diários, 21 referiram dores musculares generalizadas, sensação desagradável precordial, náusea ou tensão emocional, e que foram transitórias. Embora, em nosso material, as reações secundárias tenham sido de pequena importância e passageiras, devemos assinalar a experiência de Graham e col. ${ }^{4}$ que encontraram complicações graves quando a metisergide foi empregada em doses elevadas durante períodos prolongados.

De nossos resultados podemos concluir: 1. a metisergide tem ação anticonvulsivante satisfatória, ao menos em pacientes com epilepsia temporal; 2. a metisergide influi sôbre a atividade anormal dos focos epileptógenos, normalizando ou melhorando de maneira evidente as alterações do EEG, em elevada percentagem de casos; 3 . a metisergide atua de maneira eficaz sôbre as manifestações de tipo psíquico da epilepsia temporal; 4. a metisergide, quando administrada em doses reduzidas, não provoca reações secundárias importantes.

\section{RESUMO}

A metisergide (butanolamida do ácido 1-metil-lisérgico) foi empregada experimentalmente em 78 pacientes com epilepsia psicomotora e com alterações focais (ondas "sharp") de projeção em um dos lobos temporais, no EEG. Foram usadas doses diárias de 2 a $6 \mathrm{mg}$, associadas a $0,1 \mathrm{~g}$ de fenobarbital. Dos 78 pacientes, 59 responderam de maneira favorável ao tratamento, sendo que 47 deixaram de sofrer crises e 12 apresentaram diminuição acentuada da freqüência e intensidade das crises. As manifestações psíquicas também melhoraram com o tratamento, ao contrário do que geralmente acontece com outras drogas. As alterações eletrencefalográficas desapareceram ou melhoraram em $64 \%$ dos pacientes. Reações secundárias ocorreram em 39 dos pacientes, na fase inicial do tratamento, e foram de curta duraçāo, desaparecendo espontâneamente. 
Methysergide in the treatment of temporal lobe epilepsy

Methysergide (1-methyl-lysergic acid butanolamide) was used experimentally in 78 patients with psychomotor epilepsy and with focal abnormal activity (sharp waves) in one of the temporal lobes, in the EEG. The usual dosage of methysergide was 2 to $6 \mathrm{mg}$ daily (only 36 patients received more than $2 \mathrm{mg}$ daily) and every patient received fenobarbital $0.1 \mathrm{~g}$ daily also. Out of the 78 patients, 59 responded well to the treatment; 47 were free of seizures and in 12 there was decrease in frequency and severity of seizures. Psychic symptoms also decreased with the use of methysergide. The EEG was improved in 27 per cent of patients and became normal in 37 per cent, after twelve months of treatment. Slight side effects were reported by 39 pacients but they disappeared in a few days.

\section{REFERENCIAS}

1. ARMBRUST-FIGUEIREDO, J. A metisergide no tratamento da neuralgia do trigêmeo. Em publicação em Hospital (Rio de Janeiro).

2. ARMBRUST-FIGUEIREDO, J.; MOURA RIBEIRO, R. \& LISON, M. P. - Tratamento da enxaqueca pela metisergide. J. Bras. Med. 9:794-801, 1965.

3. FRIEDMAN, A. P. \& MERRITT, H. H. - Treatment of headache. J. Amer. Med. Ass. 163:1111-1117, 1957.

4. GRAHAM, J. R.; SUBY, H. I.; LeCOMPTE, P. R. \& SADOWSKY, N. L. Fibrotic disorders associated with methysergide therapy for headache. New England J. Med. 274:359-365, 1966.

5. HALE, A. R. \& REED, A. F. - Prophylaxis of frequent vascular headache with methysergide. Amer. J. Med. Sc. 243:92-98, 1962.

Departamento de Neurologia - Faculdade de Medicina de Ribeirão Prêto - Ribeirão Prêto, SP - Brasil. 